\title{
O LETRAMENTO DIGITAL NA FORMAÇÃO DE PROFESSORES A DISTÂNCIA ${ }^{1}$
}

\author{
Camila Miranda Machado (UECE) \\ Cleudene De Oliveira Aragão (UECE) \\ Paulo Henrique Moura Lopes (UECE)
}

Resumo: Este artigo tem por objetivo averiguar como os cursos de formação de professores na modalidade EaD abordam em seus documentos norteadores o letramento digital. Para alcançarmos nosso objetivo, analisamos o documento norteador das práticas pedagógicas do Curso Superior de Licenciatura em Letras - Espanhol na modalidade a distância do IFRN - Instituto Federal de Educação, Ciência e Tecnologia do Rio Grande do Norte. Classificamos a metodologia utilizada como uma análise documental de caráter qualitativo. Os resultados apontam uma reduzida ou nula abordagem que contemple uma formação que capacite os futuros professores para o trabalho de fomento do letramento digital em sua prática docente.

Palavras-chave: Letramento digital; Formação de professores; Ensino a distância.

Resumen: Este artículo tiene como objetivo obtener información sobre como los cursos de formación de profesores en la modalidad EaD abordan en sus documentos de base la literacidad digital. Para lograr nuestro objetivo, analizamos el documento que basa las prácticas pedagógicas del Curso Superior de Licenciatura en Letras de Lengua Española en la modalidad a distancia del IFRN - Instituto Federal de Educação, Ciência e Tecnologia do Rio Grande do Norte. Clasificamos la metodología como un análisis documental de carácter cualitativo. Los resultados apuntan para un pequeño o nulo abordaje que contemple una formación que pueda capacitar los futuros profesores para el trabajo en el ámbito digital en su práctica docente.

Palabras-clave: Literacidad digital; Formación de profesores; Enseñanza a distancia.

1 Título em língua estrangeira: "La literacidad digital en la formación de profesores a distancia" 


\section{INTRODUÇÃO}

As práticas sociais mediadas pela linguagem, seja ela verbal ou visual, vêm sofrendo grandes transformações nos últimos anos. Essas mudanças têm ocorrido de forma tão rápida que, tão logo uma modalidade discursiva surge, logo ela é transformada, adaptada ou mixada a outras. Se há quinze ou vinte anos nos maravilhávamos com os ruídos da conexão discada da internet que nos permitia novas modalidades de interação discursiva, como o e-mail, conversas on-line (ICQ, MSN Messenger), blogs, digitalização de jornais, livros, artigos que nos permitiam o acesso à informação sem limites espaciais e temporais, hoje temos incorporadas ao nosso cotidiano diversas modalidades de interação discursiva no meio digital: Whatsapp, Twitter, Facebook, Snapchat, Instagram, etc, criando novas maneiras de representação das nossas realidades e das nossas relações através da integração de diferentes recursos semióticos, ou seja, criando novas formas de multimodalidade (VAN LEEUWEN, 2011).

Desde os primeiros desenhos em paredes de cavernas, o homem usa diferentes recursos semióticos para comunicarse e assim interagir socialmente, a novidade, porém, é a variedade, a quantidade e velocidade que os recursos semióticos são criados e combinados gerando novos 
gêneros discursivos. Vivemos no que se convencionou como a Sociedade da Informação, na qual modos de agir, crenças, valores (inclusive econômicos) estão diretamente relacionados com a maneira como produzimos e consumimos informação. Ou seja, interagir através da linguagem e suas novas formas de representação siginfica também ter a capacidade de transformar o que se lê, vê e escuta em algo cada vez mais extremamente valorizado e capaz de transformar radicalmente nossos modos de vida: o conhecimento (VARÓ, 2007).

Todas essas mudanças parecem ocorrer numa velocidade muito maior do que podemos acompanhar. Quando finalmente aderimos a uma rede social, por exemplo, pode ser que esta já não esteja "na moda" e outra já a esteja substituindo (lembremos do Orkut). Todos os dias, no mundo inteiro, são criados aplicativos para tornar atividades do cotidiano mais simples, eficientes e interativas. Pegar um táxi, consultar o saldo bancário, fazer compras, acompanhar a agenda do filho na escola, são demandas nossas que hoje são resolvidas, literalmente, com o mover de um dedo. Evidentemente, essa digitalização de atividades cotidianas exige novas maneiras de lidar com a linguagem, não somente com relação às habilidades necessárias para poder interagir 
nesse novo mundo, mas também para melhor compreender, avaliar e produzir esses novos gêneros. Ou seja, exigem novos letramentos, letramentos da era digital, letramento digital (doravante LD).

Dito isso, surge a pergunta: onde desenvolver esses novos letramentos exigidos pela sociedade atual e do futuro? A resposta mais evidente seria: na escola, no entanto o que percebemos é que a escola está ainda longe de ser essa agência de LD, seja por não possuir os recursos estruturais para isso - laboratórios de informática, conexão com a internet, para dizer o mínimo - ou por não possuir professores capacitados para promover e desenvolver esses letramentos. Sobre esse último aspecto, cabe então perguntar: os cursos de licenciatura estão preparando os futuros docentes para o desenvolvimento do LD em sala de aula? Os cursos de licenciatura promovem o LD de seus alunos?

Dentro desses contextos formativos lançamos o olhar sobre a modalidade de ensino a distância (EaD), que por sua própria natureza exige desde o seu princípio um certo grau de letramentos digital, já que todo o processo de aprendizagem, ou boa parte dele - no caso de cursos semipresenciais - ocorre no meio digital. Delimitando as perguntas que pretendemos responder nesse estudo, 
indagamos: a modalidade de formação de professores a distância proporciona o desenvolvimento de seu LD? Se sim, em que grau? Capacita-o em uma pedagogia que possibilite o desenvolvimento desses novos letramentos em sua futura prática docente? Entendendo que um estudo que possa verificar essas indagações é algo muito amplo e complexo, neste trabalho tentamos iniciar a busca dessas respostas analisando um dos documentos norteadores do Curso Superior de Licenciatura em Letras - Espanhol na modalidade a distância, ofertado pelo Instituto Federal de Educação, Ciência e Tecnologia do Rio Grande do Norte (IFRN).

O artigo está organizado da seguinte forma: após essa introdução, na seção Podemos falar de tipos de letramentos?), fazemos um breve percurso histórico do surgimento dos estudos sobre letramento, além de discutir as categorizações de tipos de letramento, mais especificamente o letramento escolar, o letramento digital e o conceito de multiletramentos. Na seção Os novos-velhos desafios da formação de professores na era digital, aprofundamos as discussões e reflexões sobre as necessidades de uma pedagogia que habilite os professores em formação para uma efetiva educação para os novos letramentos. Na penúltima seção, Letramento digital na formação de 
professores a distância, realizamos uma análise documental do Projeto Pedagógico do Curso Superior de Licenciatura em Letras - Espanhol na modalidade a distância ofertado pelo IFRN verificamos se, e de que forma ocorre a promoção do letramento digital dos futuros professores. Por fim, na última seção Conclusões, buscamos retomar as perguntas realizadas no início desse estudo e dar-lhes respostas a partir das análises feitas.

\section{PODEMOS FALAR DE TIPOS DE LETRAMENTOS?}

Os estudos sobre letramento vêm já há anos suscitando discussões, estudos, teorias e trabalhos no meio acadêmico, principalmente no que se refere às suas implicações para fins pedagógicos. No Brasil, desde a definição de Mary Kato (1986) do termo em inglês literacy como letramento, passando pelos primordiais e definidores conceitos de Kleiman (1995) e Soares (2012), são inúmeros os artigos, dissertações, teses, livros, conferências, congressos e simpósios sobre letramento. A partir do advento do termo e seu entendimento como algo relacionado diretamente com a prática sociodiscursiva, ou seja, como um processo que é tão variado quantos são variados os contextos comunicativos humanos, surgiram as categorizações de tipos de letramento: letramento crítico, letramento literário, letramento escolar, 
letramento digital, multiletramentos, etc. Como nesse trabalho investigamos as relações entre a formação de professores e o LD, trataremos então especificamente sobre letramento escolar, LD e multiletramentos.

\subsection{Letramento escolar}

Sobre letramento escolar, Soares (2004) afirma que seu conceito está diretamente relacionado às concepções de eventos e práticas de letramento. Define-se evento de letramento como

parte integrante da natureza da interação entre participantes e de seus processos de interpretação, seja uma interação face a face, em que pessoas interagem oralmente com a mediação da leitura ou escrita, ou por interação à distância, autor- leitor ou leitorautor. (HEATH Apud SOARES, 2004, p.105)

Por práticas de letramento apontamos em nosso trabalho a contribuição de Street que diz, "tanto os comportamentos exercidos pelos participantes num evento de letramento, quanto as concepções sociais e culturais que o configuram, determinam sua interpretação e dão sentido aos usos da leitura e/ou escrita naquela particular situação." (STREET Apud SOARES, 2004, p.105)

Após nos apresentar as definições de eventos e práticas de letramento, Soares (2004) compara suas diferenças na 
vida cotidiana e no contexto escolar. Portanto, tratando da vida cotidiana, eventos e práticas de letramento surgem em um contexto da vida social ou profissional, são de interesse pessoal ou de grupos, sendo então vividos e interpretados de maneira natural e espontânea.

No contexto escolar os eventos e práticas escolares são planejados, estabelecidos, selecionados levando em consideração os critérios e interesses pedagógicos e visando à aprendizagem, sendo conduzido por atividades avaliativas, além de possuir um objetivo destinado. Dessa maneira, a escola encaminha os eventos e práticas de letramento de acordo com as circunstâncias e práticas sociais determinadas por ela.

\subsection{Letramento digital (LD)}

Tratando de letramento digital, Ribeiro (2010) afirma que seu conceito ainda é considerado controverso, uma vez que além de carregar em sua terminologia o termo letramento já tomado por objeto de debate, traz também um adjetivo que transforma seu sentido, dessa forma, a autora afirma que letramento digital ainda não é uma expressão aplicada irrestritamente. No Brasil, diversos pesquisadores adotaram essa terminologia, uma vez que ela admite um leque infinito de possibilidades de dispositivos que empreguem a tecnologia digital. 
Ainda tratando sobre o conceito de letramento digital Soares (2012) corrobora essa visão ao afirmar que este termo é considerado polissémico, uma vez que pode trazer diferentes concepções. Dessa forma, letramento digital pode estar associado à alfabetização digital, estando inteiramente relacionada a uma visão mais tecnicista e instrumental das habilidades de utilização das Tecnologias da Informação e Comunicação ou poderá também estar ligada a uma visão mais crítica e produtiva das tecnologias, observando o contexto sociocultural, histórico e político o qual está imerso o processo do letramento digital.

Buzato (Apud RABELLO; HAGUENAUER, 2014, p.203) adota um sentido mais amplo de letramento digital, associado às práticas sociais, se opondo, dessa forma, à restrição de habilidades e competências instrumentais. Como observamos em sua definição abaixo:

Letramentos digitais (LDs) são conjuntos de letramentos (práticas sociais) que se apóiam, entrelaçam e apropriam mútua e continuamente por meio de dispositivos digitais para finalidades específicas, tanto em contextos socioculturais geograficamente e temporalmente limitados, quanto naqueles construídos pela interação mediada eletronicamente. (BUZATO, 2006, p.16)

Freitas (2010) também se apoia a um conceito mais amplo de letramento digital. Para a autora, este termo está vinculado a práticas sociais e culturais. Nesse sentido, define letramento digital como: 
Conjunto de competências necessárias para que um indivíduo entenda e use a informação de maneira crítica e estratégica, em formatos múltiplos, vinda de variadas fontes e apresentada por meio do computador-internet, sendo capaz de atingir seus objetivos, muitas vezes compartilhados social e culturalmente. (2010, p.339, 340)

A partir de sua definição, Freitas tece algumas observações sobre a importância da formação do professor diante do letramento digital. Para a autora, por sua experiência nesta área, observa-se que apenas a estrutura da escola equipada de computadores e internet, além da formação básica sobre conhecimento de informática, não tem sido o bastante para que haja uma integração entre os recursos digitais disponíveis e as práticas pedagógicas dos docentes. A autora sugere então, que os professores se apropriem crítica e criativamente da tecnologia, compreendendo o letramento digital não apenas restrito ao uso instrumental.

Ribeiro (2010) afirma que para alcançar algum grau de letramento digital "são necessários obter conhecimentos que vão desde o conhecimento de gestos e o uso superficial do computador, além da leitura de vários gêneros sofisticados publicados on-line e exibidos no monitor" (2010. p.33).

Assim sendo, concebemos o LD para fins de nossa investigação baseados nos conceitos propostos por Buzato 
(2016) e Freitas (2010), ou seja, como esse conjunto de práticas sociais localmente contextualizadas, multimodais, multisemióticas e mediadas pelo meio digital.

\subsection{Multiletramentos}

Tratando dos multiletramentos, Rojo (2012) afirma que a proposta da pedagogia dos multiletramentos surge com o "Grupo de Nova Londres", estes defendiam a incorporação na prática escolar da pluralidade das mídias, de linguagens e culturais que foram incorporadas na sociedade por meio das novas tecnologias da comunicação e da informação. Dessa forma, o centro das pesquisas dos estudiosos dos multiletramentos é o contexto do ensino, a fim de repensar habilidades fundamentais para a participação dos aprendizes em práticas letradas multisemióticas. A autora ressalta ainda que na década de 1990 as mudanças ocasionadas pela legislação nacional (Lei das Diretrizes e Bases 9394/96) fizeram com que os estudos sobre a formação docente inicial ou continuada fossem mais intensos.

Tratando da formação de professores na abordagem do multiletramento, (ROSERNBERG Apud RABELLO; HAGUENAUER, 2014, p.213) afirma que para que os professores desenvolvam uma aprendizagem voltada ao empoderamento dos alunos por meio de práticas 
de multiletramentos é preciso que os docentes estejam imersos às práticas de multiletramentos semelhantes aos de seus alunos, para isso é de fundamental importância:

1) que os materiais didáticos estejam em consonância com a consciência dos novos meios; 2) a utilização por parte dos professores de materiais não formais e contextos não formais de formação como a criação de blogs, chats; 3) o reconhecimento da pedagogia sobre o ensino do letramento por meio das TICs e 4) o reconhecimento também da pedagogia frente ao empoderamento dos professores em conexão com uma abordagem aos multiletramentos pra tornar com êxito dos professores e alunos letrados na nova ordem mundial.

\section{OS NOVOS-VELHOS DESAFIOS DA FORMAÇÃO DE PROFESSORES NA ERA DIGITAL}

A escola ainda é a principal agência de letramento. É na escola que a maioria de nós aprende a decifrar o código linguístico, somos instruídos nas primeiras leituras e interagimos com distintos tipos de textos (verbais e não verbais). São anos e anos desenvolvendo a capacidade de leitura e escrita que deveria nos preparar para as demandas de uma sociedade na qual as relações humanas são mediadas pela linguagem. No entanto, além de percebermos que nosso sistema educacional é falho nessa promoção mínima 
de letramento ${ }^{2}$, a escola não tem acompanhado as mudanças nas novas demandas sociais mediadas pela linguagem, principalmente no que se refere à promoção de letramento digital. Nas palavras de Barbosa, Araújo e Aragão,

\begin{abstract}
se por um lado estamos diante de um contexto social no qual eventos comunicativos são realizados por meio de diferentes linguagens, com múltiplos modos e recursos semióticos, e de diferentes meios, com as tecnologias presentes cada vez mais em nosso cotidiano, por outro lado, mesmo diante da produção de hipertextos multimodais voltados para o processo de ensino-aprendizagem, não podemos afirmar que no contexto educacional as práticas pedagógicas estejam congruentes com um cenário que, a cada dia, gera novos letramentos. (2016, p.625)
\end{abstract}

Essa discrepância entre o contexto social e o contexto pedagógico, destacado pelas autoras, só tende a aumentar na medida que as novas tecnologias criam novas formas de interação com o mundo. De acordo com Rojo (2011), a escola comumente pratica um modelo de letramento com uma visão unívoca, individual (letramento autônomo), sem considerar esse processo como algo situado e socialmente construído (letramento ideológico). A escola ainda está longe de promover uma pedagogia dos multiletramentos,

2 De acordo com o relatório do Programme for International Student Assessment (Pisa) de 2015, no que se refere à avaliação de leitura, o Brasil apresenta uma das piores médias em comparação com outros países da América Latina. 
ou seja, uma proposta didática que valorize a diversidade sociocultural e a variedade de semioses nos distintos contextos da comunicação humana (ROJO, 2012).

Vale ressaltar que dois documentos basilares da educação no Brasil, os Parâmetros Curriculares Nacionais (PCNs) e as Orientações Curriculares para o Ensino Médio (OCEM) já têm 21 e 12 anos, respectivamente, o que nesses tempos das novas tecnologias representa uma defasagem muito grande, não contemplando os novos letramentos digitais necessários atualmente. Por outro lado, se analisarmos a Base Nacional Curricular Comum (BNCC) referente ao Ensino Médio³, por exemplo, no que se refere às competências específicas da área de Linguagens e suas Tecnologias, afirma que

é importante que os estudantes
compreendam o funcionamento e os
recursos oferecidos pela tecnologia digital
para o tratamento das linguagens (mixagem,
sampleamento, edição, tratamento de
imagens etc.), assim como as possibilidades
de remidiação abertas pelos fenômenos
multimídia e transmídia, característicos
da cultura da convergência. (BRASIL, 2017,
p.483)

Ou seja, o documento que irá nortear os currículos das redes de ensino parece estar, pelo menos em uma primeira

3 A BNCC "é um documento de caráter normativo que define o conjunto orgânico e progressivo de aprendizagens essenciais que todos os alunos devem desenvolver ao longo das etapas e modalidades da Educação Básica" (BRASIL, 2017, p.7). No dia 4 de dezembro de 2018 foi aprovada pelo Conselho Nacional de Educação a versão que citamos, atualmente em revisão. 
análise, a par dessas novas demandas e as inclui numa futura formação educacional brasileira. No entanto, essa mudança, essa "atualização de programa" será efetiva? Evidentemente acontecerá na medida que aqueles que estão na base desse processo entendam essas mudanças e se capacitem para promovê-la, ou seja, é urgente a necessidade de que os professores se preparem para essa educação 2.0. De acordo com Pereira (2007, p.21), "Esse novo ambiente tecnológico tem importância fundamental para a educação e para a formação", e mais adiante acrescenta:

O pessoal docente, em especial educadores e professores, precisa melhorar sua qualificação em termos de tecnologia. Numa economia global, cada vez mais baseada no conhecimento, a exclusão digital põe em risco o futuro do país. (PEREIRA, 2007, p.21)

O olhar do pesquisador então se direciona para a agência de letramento dos futuros agentes de letramento, ou seja, se direciona para a formação docente. As demandas comunicativas exigem dos professores conhecimentos e capacidades que não foram desenvolvidas em sua formação. E como superar o problema? Simplesmente tornar nossos professores experts no uso das novas tecnologias? Buzato (2006), além de evidenciar questões de infraestrutura (compra de computadores, conexões velozes com a internet), 
chama a atenção para não cairmos na tentação de que "tudo é lindo no mundo maravilhoso das redes virtuais" (2006, p.12). Sobre a formação de professores nesse novo contexto, o autor afirma também que

Precisamos de formadores que saibam o que dizem, mas que sejam mediadores, construtores de comunidades de prática nas quais os professores possam ir se integrando de forma natural e significativa, tendo em mente seu próprio contexto de trabalho e suas necessidades de formação. (BUZATO, 2006, p.12)

Em outras palavras, é preciso que os professores sejam capacitados para atuarem com essas novas tecnologias da comunicação em seus contextos de trabalho, de forma colaborativa com seus alunos. É preciso que o professor e o formador compreendam que a hierarquia do saber foi rompida, que aqueles a quem devem capacitar, muitas vezes, possuem letramento digital muito superior ao dele. Não é uma simples questão de treinamento, mas de "entrelaçamentos, apropriações e transformações entre o que tínhamos e sabíamos fazer e o que queremos ter e precisamos aprender a fazer." (BUZATO, 2006, p.13).

Passamos então, agora, à nossa análise de como está prevista, pelo menos nos documentos norteadores curriculares, o fomento do letramento digital na formação de professores a distância. 


\section{LETRAMENTO DIGITAL NA FORMAÇÃO DE PROFESSORES A DISTÂNCIA}

A relação entre tecnologia e educação não é algo recente. Segundo Saraiva (2010), desde o século XV, com o advento da imprensa por Gutemberg, passando pelos serviços de correspondência no século XVIII que ofereceram os primeiros cursos a distância nos EUA, chegando até o século XX com cursos oferecidos por rádio e a partir dos anos 90 com a criação dos ambientes virtuais de aprendizagem (AVA) na internet, tem-se buscado maneiras de ampliar as possibilidades de educação para além dos tempos e dos espaços mais limitados da educação regular em sala de aula. A EaD, ainda segundo Saraiva (2010), trata-se de qualquer processo de ensino-aprendizagem mediado por algum tipo de tecnologia, no qual professor e aluno não ocupam o mesmo lugar físico de forma simultânea. Nos seus primórdios, essa modalidade oferecia cursos de ordem extremamente prática, como o primeiro curso de datilografia por correspondência que se tem registro no Brasil no final do século XIX. Ainda de acordo com Saraiva (2010), as primeiras experiências exitosas no Brasil nessa modalidade de grande abrangência foram a do Instituto Rádio-Monitor (1939) e a do Instituto Universal Brasileiro (1941), em atuação até os dias de hoje. 
No que se refere ao Ensino Superior, o ensino a distância data do século XIX, quando a Universidade de Londres oferta pela primeira vez um curso por correspondência. De acordo com Saraiva (2010), ao referir-se a esses primeiros cursos universitários ofertados por correspondência "ensinavam ofícios de pouco reconhecimento social e eram dirigidos, em sua maioria, a trabalhadores sem condições de estudar de forma regular" (SARAIVA, 2010, p.30). Seguindo nessa historiografia da EaD, a autora menciona a criação da Open Universitiy (Inglaterra), a Fern Universität, (Alemanha), a Universidad Nacional de Educación a Distancia (UNED), na Espanha, Universidad Abierta de Venezuela e a Universidad Estatal a Distancia (Costa Rica). No Brasil, só após a década de 90 a EaD começou a se estabelecer na oferta de cursos superiores. O seu marco foi a Lei 9.394/96 (LDB) que no seu Art. 80 estabelece que o poder público deverá incentivar o desenvolvimento e regular a oferta de programas de ensino a distância em todos os níveis e modalidades de ensino.

No que se refere especificamente à formação de professores, até 2009, de acordo com dados do Ministério da Educação (MEC), cursos na modalidade a distância já representavam $48 \%$ das vagas ofertadas por universidades e institutos federais. Embora esses dados já estejam bastante 
defasados, já indiciava há quase 10 anos atrás a forte tendência de os cursos superiores de formação de professores serem ofertados na modalidade EAD. Saraiva (2006) destaca que, segundo a Secretaria de Ensino Superior, de 1998 até 2006 há um crescimento acentuado de instituições de ensino superior credenciadas a ofertar cursos a distância. Ainda segundo dados do MEC, a maioria desses cursos, até 2006, eram relacionados a formação de professores ou profissionais da área de educação. Num contexto mais próximo, por exemplo, temos o Instituto Universidade Virtual, ligado à Universidade Federal do Ceará (UFC), que oferece sete cursos de licenciatura, e o Instituto Federal do Rio Grande do Norte (IFRN), que oferta duas licenciaturas.

Diante de tudo aqui já exposto, temos dois fatos: 1) a urgência de que professores e demais profissionais da educação possuam um grau satisfatório de letramento digital para que possa desenvolver com seus alunos esse mesmo letramento, e 2) a existência de um grande número de professores formados através da educação a distância. Relacionando os dois pontos, poderíamos crer que os professores formados através da $\mathrm{EaD}$, por sua própria natureza de uma aprendizagem mediada pela tecnologia, possuam um maior grau de letramento digital, ou pelo menos, 
sua formação Ihe possibilita um melhor desenvolvimento do letramento nessa área, em comparação aos professores formados pela modalidade presencial. A sala de aula do professor formado pela EaD é um AVA, as interações com o professor e demais colegas ocorrem através de gêneros discursivos do meio digital (fóruns, chats, mensagens, e-mails). No entanto, sabemos que o conhecimento desses gêneros, ou o manuseio de ferramentas web não indicam que o docente saiba desenvolver pedagogicamente em seus alunos o letramento digital. De acordo com Saraiva (2006):

As transformações dos professores [...] vão além da apropriação do funcionamento da tecnologia e seus efeitos, criando uma nova identidade do professor. O posicionamento do professor frente à educação via internet deveria vir acompanhado de mudanças em seu perfil profissional, em suas práticas e no aporte teórico-epistemológico que as sustentam. (p.156, grifo nosso)

Essa mudança de perfil precisa então de um embasamento teórico-epistemológico. Não vai e não pode ocorrer simplesmente porque se está dizendo que é preciso. Só efetivamente teremos uma mudança se na sua formação o professor tiver acesso a essas novas práticas pedagógicas mediadas pela tecnologia e formas de aplicá-las em sua sala de aula. O próprio professor formador, na modalidade EaD, 
deve ser esse profissional que entenda a relação tecnologiaaprendizagem como algo mais do que uma possibilidade instrumental, mas como uma nova postura de interação com as novas mídias, os novos gêneros e os letramentos necessários para poder formar sujeitos atuantes na sociedade da informação. De acordo com Nogueira (2004),

É importante ressaltar, neste momento, que na utilização desta modalidade de educação, com a intermediação da tecnologia informática, o papel do professor deverá ser o de buscar a construção de indivíduos criativos e produtores de saber, o que pressupõe a elaboração de uma base afetiva necessária às estruturações e reestruturações cognitivas, tendo-se em vista um desenvolvimento psicológico cada vez mais pleno e autônomo. (2004, p.108)

O que buscamos verificar então é se de fato essa modalidade de ensino proporciona essa mudança no perfil de seus professores em formação, dando-lhes os aportes teóricos-epistemológicos para que possa de fato compreender o uso das novas tecnologias no processo de ensino e aprendizagem, tendo a capacidade de desenvolver o seu próprio letramento digital e apropriar-se de práticas pedagógicas que possam desenvolver esse mesmo letramento nos seus alunos. Para isso, passamos agora à análise de um dos documentos norteadores do curso de licenciatura ofertado por pela instituição citada. 


\section{ANÁLISE DO DOCUMENTO}

Nesta seção, detalhamos a análise documental feita por nós, indicando nosso contexto de pesquisa, a metodologia utilizada para obtenção dos dados e os procedimentos de pesquisa. Além disso, apresentamos e comentamos os dados obtidos à luz dos estudos até aqui apresentados sobre letramento digital e formação de professores.

\subsection{Contexto de pesquisa, metodologia e procedimentos}

A fim de verificar de que forma os cursos de formação de professores EaD proporcionam, pelo menos de maneira regimentar, o letramento digital dos seus discentes, buscamos analisar o Projeto Pedagógico do Curso Superior de Licenciatura em Letras Espanhol na modalidade a distância ofertado pelo IFRN. Trata-se de uma pesquisa documental de caráter qualitativo. Segundo Godoy (1995), nesse tipo de pesquisa, três aspectos devem ser considerados primeiramente pelo investigador: a escolha do documento, o acesso a ele e a sua análise. Sobre a escolha do documento, afirmamos que se trata de um documento norteador dos fazeres acadêmicos de qualquer curso, incluindo sua grade curricular. Sobre o acesso, além de se tratar de um documento disponível na internet, por nossa vinculação institucional ${ }^{4}$, temos um fácil acesso a demais informações

4 Um dos autores desse estudo, Paulo Henrique Moura Lopes, é professor efetivo do IFRN. 
do referido curso. No que tange à análise em si, optamos pela metodologia mais usada na análise de documentos (BARDIN Apud CÂMARA, 2013): a análise de conteúdo 5 . Apresentamos agora os resultados encontrados e os comentamos.

\subsection{Dados e análise}

A partir de agora apresentamos o resultado de nossa análise do documento orientador do curso. Buscamos, através de sua leitura, possíveis indicações de como está previsto nos seus objetivos, princípios teóricos-epistemológicos, perfil de formação e matriz curricular o letramento digital de seus discentes.

Logo no início, no tópico Introdução, evidencia-se a correta concepção de um fazer e saber pedagógico relacionado com o contexto social de ensino. Segundo o próprio documento,

o ato de ensinar nas licenciaturas oferecidas pelo IFRN é concebido como uma atividade humana, técnica, política e ética voltada para a formação da cidadania e para o mundo do trabalho, por meio de um currículo que ressalta - no que concerne à formação de professores - as exigências filosóficas, epistemológicas e as necessidades do contexto social. (BRASIL, 2012, p.7)

5 Segundo Bardin (Apud Câmara, 2013, p.182), esse tipo de análise se faz através de "um conjunto de técnicas de análise das comunicações visando a obter, por procedimentos sistemáticos e objetivos de descrição do conteúdo das mensagens, indicadores (quantitativos ou não) que permitam a inferência de conhecimentos relativos às condições de produção/recepção (variáveis inferidas) destas mensagens". 
Espera-se então, dentro dessa perspectiva de uma formação voltada para a cidadania e para o mundo do trabalho, que implica na formação de um professor segundo as necessidades e exigências do contexto social, o desenvolvimento do letramento digital. Ainda segundo o documento, um dos objetivos da EaD no IFRN é favorecer a inclusão digital, fundamental numa sociedade que exige o uso das Novas Tecnologias da Informação e da Comunicação (NTIC). Ainda com relação a esse objetivo, afirma-se no documento que

formar-se através de um curso em EaD permite ao indivíduo não só a sua qualificação profissional na área específica em que atua ou pretende atuar, mas a sua inclusão no universo digital. Assim, os cursos em EaD atingem dois objetivos de inclusão em uma só oferta. (BRASIL, 2012, p.8)

$\mathrm{Na}$ adoção de suas linhas estratégicas de implementação da EaD no IFRN, destacamos dois pontos:

a) Estimular e orientar o corpo docente deste Instituto a utilizar as tecnologias de informação e comunicação (TIC's), como instrumento de ensino, aprimorando, dessa forma, o processo didático;

b) Democratizar o uso crítico das NTIC.

Com relação aos objetivos e às linhas estratégicas da EaD no IFRN, podemos observar que estão inteiramente de acordo com os aportes teóricos mais vigentes (BUZATO, 
2006; SARAIVA, 2006; PEREIRA, 2007). No entanto, não está explícito no documento de que forma essa inclusão digital, através da incorporação das NTICs ocorre efetivamente.

Passando à análise do que o documento rege especificamente sobre o Curso Superior de Licenciatura em Letras - Espanhol, dos três pontos elencados como objetivos, não há nenhuma menção a como proporcionar ao futuro professor letramento digital ou o aporte teóricoepistemológico para que possa desenvolvê-lo na sua prática pedagógica futura. Igualmente, ao tratar do perfil do futuro profissional formado no curso, não há essa menção, a não ser o ponto que afirma que o licenciado será capaz de adotar estratégias de utilização de novas ideias e tecnologias, o que a nosso ver não é suficiente claro para a construção de um perfil profissional de acordo com as novas demandas aqui já referidas. Prosseguindo, ainda com relação aos princípios de bases filosóficas e epistemológicas que dão suporte à estrutura curricular do curso, dos 15 pontos elencados, não há um único que faça menção ao desenvolvimento do letramento digital ou da capacidade de interação com os novos gêneros digitais.

Prosseguimos agora à análise da Matriz Curricular do curso. São ofertadas 59 disciplinas distribuídas em quatro 
núcleos: fundamental, didático-pedagógico, epistemológico e específico, além da Prática Profissional. De um total de 2.520 horas destinadas à formação docente, 2.220 horas são de disciplinas obrigatórias e 300 horas mínimas de disciplinas eletivas. Dessas disciplinas, para fins de nossa análise, destacamos a disciplina de Mídias Educacionais, de caráter obrigatório e pertencente ao Núcleo Didático-Pedagógico, prevista para o 60 período do curso e com 80 horas/aula. Passamos agora para uma breve apreciação do Programa da disciplina.

A disciplina de Mídias Educacionais prevê em sua ementa a integração de novas tecnologias educacionais no processo de ensino de língua espanhola. No entanto, nos chama atenção alguns dos objetivos elencados para a disciplina, tais como:

Analisar de forma crítica o uso de recursos tecnológicos educacionais em instituições de ensino a nível local, estadual e internacional;

Utilizar recursos tecnológicos para facilitar o pensamento em níveis complexos e críticos, incluindo a resolução de problemas, construção do conhecimento e criatividade;

Utilizar recursos tecnológicos para localizar, avaliar e colher informações provenientes de diversas fontes;

Avaliar e selecionar novos recursos para obtenção de informações e inovações 
tecnológicas, baseadas nas adequações para tarefas específicas;

Usar uma variedade de mídias e formatos, incluindo telecomunicações, para colaborar, publicar e interagir com colegas, especialistas e outros.

Todos os objetivos acima elencados parecem se encaixar na definição de LD de Buzato (2006) e Freitas (2010) (op. cit. p.6), referindo-se tanto ao desenvolvimento do LD do próprio professor em formação como o de seus futuros alunos. Evidentemente que entre o que é estabelecido como objetivo de uma disciplina e o resultado final do processo, pode haver uma grande discrepância, exigindo então uma análise mais detalhada através de um acompanhamento da disciplina. Porém, já é pelo menos um indicativo estabelecer em seus objetivos de aprendizagem metas que condizem com o desenvolvimento do LD.

A análise dos conteúdos da disciplina também é alentadora, no que diz respeito à promoção do $L D$, além de uma pedagogia de multiletramentos multimodais. Nos referimos especialmente a conteúdos como Elaboração Coletiva dos Conceitos de Tecnologia Educacional, Mídias Educacionais e Multimídia; Análise Crítica do Uso de Mídias Educacionais nas Escolas do RN e Fora do Brasil; O Trabalho do Professor e as Novas Tecnologias Educacionais (Nativos e Imigrantes 
Digitais); Integrando Recursos da Internet (Sites, Blogs, Wikis, Redes Sociais, etc.) nas Aulas e nos Projetos Educacionais de Espanhol; Introduzindo Educação a Distância (Noções sobre Objetos de Aprendizagem online); Pesquisando Novos Produtos Tecnológico-Educacionais (Quadros Interativos, tablets; etc.). Considerando que o documento em análise é de 2012, os conteúdos ainda parecem estar atualizados com o que se promulga hoje com relação a pedagogia dos multiletramentos (ROJO, 2012) e o que prevê a recémaprovada BNCC do Ensino Médio.

\section{CONSIDERAÇÕES FINAIS}

O objetivo desse trabalho foi o de verificar de que forma o LD é promovido num curso de formação de professores na modalidade EaD. Retomando as perguntas norteadoras que realizamos no início desse estudo (a modalidade de formação de professores a distância proporciona o desenvolvimento de seu letramento digital? Se sim, em que grau? Capacita-o em uma pedagogia que possibilite o desenvolvimento desses novos letramentos em sua futura prática docente?), através da análise do documento norteador das práticas pedagógicas do Curso Superior de Licenciatura em Letras Espanhol na modalidade a distância do IFRN.

Embora tenhamos realizado uma análise documental referente a apenas um curso, através de nosso estudo, 
pudemos verificar que pelo menos no que diz respeito aos objetivos programáticos do curso, apenas uma disciplina do sexto período, Mídias Educacionais, parece prever em sua elaboração o desenvolvimento do LD do discente no que diz respeito à sua futura prática docente. Acreditamos que se os objetivos forem plenamente alcançados e os conteúdos previstos sejam constantemente readaptados às novas realidades das possibilidades multimodais de comunicação, há sim uma capacitação do futuro profissional para promover o LD entre seus alunos.

Por outro lado, chamou nossa atenção a pouca ou quase nenhuma menção no documento de forma geral à importância de uma formação docente que contemple as novas exigências socio discursivas da Sociedade da Informação. Acreditamos que todas as disciplinas, incluindo as no núcleo específico de formação, possam contemplar em sua matriz programática o LD. O que propomos é uma formação que esteja em sua totalidade integrada com as novas tecnologias e os novos gêneros digitais, pois as fronteiras da comunicação entre o real e o virtual hoje são híbridas e muitas vezes impossíveis de delimitar. No que se refere ao professor de língua espanhola em formação, por exemplo, a prática de leitura, a literatura, os aspectos socioculturais, o ensino de estruturas linguísticas, a prática fonética, etc., não podem 
ser desenvolvidas sem levar em conta os novos letramentos exigidos na comunicação humana. Ou seja, o LD não pode ser tema de uma única disciplina, é preciso ser pensado e promovido desde o início da formação e permanecer em constante processo de desenvolvimento durante toda a vida profissional do professor.

Estamos conscientes de que aqui tratamos de um caso específico de análise documental, sem levar em conta aspectos mais amplos e complexos como o efetivo desenvolvimento do LD nos alunos do curso. Como propostas de futuras pesquisas, sugerimos um estudo longitudinal que possa avaliar o grau de LD desses discentes no início e no final da disciplina de Mídias Educacionais, verificando através de metodologias de coleta de dados mais pertinentes (entrevistas, questionários, testes com categorias de análise) se de fato a disciplina cumpre o que propõe. Conclusivamente, acreditamos que nosso estudo possa ter colaborado para traçar um panorama da promoção do LD na formação de professores na modalidade EaD.

\section{REFERÊNCIAS}

BARBOSA, Vânia Soares; ARAÚJO, Antonia Dilamar; ARAGÃO, Cleudene de Oliveira. (2016) "Multimodalidade e multiletramentos: análise de atividades de leitura em meio digital". Revista brasileira de linguística aplicada, 16(4), 623-650, Dez. Belo Horizonte. In http://www. scielo.br/scielo.php?pid=S1984-63982016000400623\&script $=$ sci_ abstract\&tlng=pt Acesso em 21.Ago.2018. 
BRASIL (2012). Projeto Pedagógico do Curso Superior de Licenciatura em Letras Espanhol na modalidade a distância. Instituto Federal de Educação, Ciência e Tecnologia do Rio Grande do Norte. In http://portal.ifrn.edu.br/ ensino/cursos/cursos-de-graduacao/licenciatura/licenciatura-em-letrasespanhol-educacao-a-distancia/view Acesso em 30.Nov.2018.

BRASIL. Ministério da Educação (2016). Brasil no PISA 2015: análises e reflexões sobre o desempenho dos estudantes brasileiros / OCDEOrganização para a Cooperação e Desenvolvimento Econômico. São Paulo: Fundação Santillana. In http://download.inep.gov.br/acoes_ internacionais/pisa/resultados/2015/pisa2015_completo_final_baixa.pdf Acesso em 4.Dez.2018.

(2018). Base Nacional Curricular Comum: Ensino Médio. In http://portal.mec.gov.br/index.php?option=com_ docman\&view=download\&alias=85121-bncc-ensino-medio\&category_ slug=abril-2018-pdf\&ltemid=30192 Acesso em 1.Dez.2018.

BUZATO, Marcelo El Khouri (2006). Letramentos digitais e formação de professores. III Congresso Ibero-Americano EducaRede: Educação, Internet e Oportunidades. São Paulo. In https://www.academia. edu/1540437/Letramentos_Digitais_e_Forma\%C3\%A7\%C3\%A3o_de_ Professores Acesso em 4.Dez.2018.

CAMARA, Rosana Hoffman (2013). "Análise de conteúdo: da teoria à prática em pesquisas sociais aplicadas às organizações". Revista Interinstitucional de Psicologia, 6(2), 179-191, Jul.-Dez. Belo Horizonte. In http://pepsic.bvsalud.org/scielo.php?script=sci_arttext\&pid=S1983$82202013000200003 \&$ lng=pt\&nrm=iso Acesso em 15.Jan.2019.

CASSANY, Daniel (2006). Tras las líneas. Sobre la lectura contemporánea. Barcelona: Anagrama, p.21-43.

FREITAS, Maria Teresa (2010). "Letramento digital e formação de professores". Educação em Revista, 26(3), Dez, 335-352. Belo Horizonte: UFMG. In http://www.scielo.br/scielo.php?script=sci_arttext\&pid $=$ S0102-46982010000300017 Acesso em 02.Dez.2018.

NOGUEIRA, Mário Lúcio de Lima (2004). Tópicos Especiais em Educação Inclusiva: estigmas e preconceitos. Curitiba: IESDE. 
PEREIRA, João Thomaz (2007). "Educação e Sociedade da Informação". In: COSCARELLI, Carla Viana; RIBEIRO, Ana Elisa (Orgs.). Letramento digital: aspectos sociais e possibilidades pedagógicas. São Paulo: Autêntica Editora.

RABELLO, Cíntia Regina Lacerda; HAGUENAUER, Cristina Jasbinchek (2014). "Tecnologias, novos letramentos e formação de professores para/na Cibercultura". In: HAGUENAUER, Cristina Jasbinschek; ULBRICHT, Vania Ribas; LIMA, Luciana Guimarães Rodrigues de (Orgs.). Pesquisas em linguagem e educação no contexto das tecnologias digitais. Curitiba: CRV. RIBEIRO, Ana Elisa (2009). "Letramento digital: um tema em gêneros efêmeros". Revista da ABRALIN, 8(1), Jan.-Jun., 15-38. In https://revistas. ufpr.br/abralin/article/view/52433/32273 Acesso em 02.Dez.2018.

ROJO, Roxane (2001). "Letramento escolar em três práticas: perspectivas para a multivocalidade”. Revista da ANPOLL, 11, 235-262, Jul./Dez.

(2012). "Pedagogia dos multiletramentos". In: ROJO, Roxane.; MOURA, Eduardo (Orgs.). Multiletramentos na escola. São Paulo: Parábola Editorial.

SARAIVA, Karla Schuck (2010). Educação a distância: outros tempos, outros espaços. Ponta Grossa: Editora UEPG.

SOARES, Magda (2004). "Letramento e Escolarização". In: RIBEIRO, Vera Masagão (Org.). Letramento no Brasil. São Paulo: Global.

VAN LEEUWEN, Theo (2011). "Multimodality". In: SIMPSON, James (Ed.). The Routledge handbook of applied linguistics. New York: Routledge. p.668-682.

VARÓ, Enrique Alcaraz (2007). "La sociedad del conocimiento, marco de las lenguas profesionales y académicas". In: VARÓ, Enrique Alcaraz; MARTÍNEZ, José Mateo; RAMOS, Francisco Yus (Orgs.). Las lenguas profesionales y académicas. Barcelona: Ariel Lenguas Modernas.

Camila Miranda Machado é Mestranda em Linguística Aplicada pela Universidade Estadual do Ceara (UECE). Bolsista da Fundação Cearense de Apoio ao Desenvolvimento Científico e Tecnológico (FUNCAP). 
Monografia intitulada: Uso de cuentos para la enseñanza de la interacción oral en las clases de español lengua extranjera. Participa do grupo de pesquisa Literatura: Estudo, Ensino e (Re)leitura do mundo (GP LEER). E-mail: camilamiranda_m@hotmail.com

Cleudene de Oliveira Aragão é Doutora em filología hispánica pela Universidad de Barcelona. UECE. Graduação, Mestrado e Doutorado. BARBOSA, VÂNIA SOARES; ARAÚJO, ANTONIA DILAMAR; ARAGÃO, CLEUDENE DE OLIVEIRA (2016). "Multimodalidade e multiletramentos: análise de atividades de leitura em meio digital". Revista Brasileira de Linguística Aplicada, 16, 623-650. MOREIRA, G. L. (Org.); ARAGÃO, C. O. (Org.); SILVA, G. M. (Org.); FALCAO, C. A. (Org.) (2013). Reflexões e ações no ensino e aprendizagem de Espanhol/LE. (EDUECE). v.1. 315p. TORRES, G. F. G.; ARAGÃO, C. O. (2014). A Literatura Como Recurso Para O Desenvolvimento Do Letramento Crítico: Uma Proposta Baseada Em Gêneros Textuais. Interletras (Dourados), v.3, p.1-12; PARENTE, L. O. S. S.; ARAUJO, S. S.; ARAGÃO, C. O. (2018). "A Formação De Leitores Literários No Contexto Escolar No Brasil: Desafio Para Professores E Para Toda A Sociedade Brasileira". In: Francisco Ari de Andrade; Getuliana Sousa Colares; Dijane Maria Rocha Víctor. (Org.). Educação, limites e possibilidades. Curitiba: Editora CRV. v.1, p.217-228. Grupo de pesquisa Literatura: Estudo, Ensino e (Re)leitura do mundo (GP LEER). E-mail: cleudene.aragao@uece.br

Paulo Henrique Moura Lopes é Mestre em Linguística Aplicada e Doutorando em Linguística Aplicada pela UECE.. A leitura de obras literárias nos cursos de língua estrangeira: de justificativa parta avaliação oral a um uso eficaz para o fomento da competência leitora (Dissertação); A leitura de obras literárias nos cursos de E/LE: seu espaço e sua função (Artigo). Grupo de pesquisa Literatura: Estudo, Ensino e (Re)leitura do mundo (GP LEER).

E-mail: paulo.moura@aluno.uece.br 